\title{
Limits to protection
}

Marine protected areas can support ecosystem resilience in the face of environmental stress, but only up to a point.

A marine heatwave in 2016 killed nearly one third of the living corals on Australia's Great Barrier Reef, and a subsequent heatwave in 2017 killed many more ${ }^{1}$. The unprecedented loss of corals in 2016 was concentrated in the northern third of the reef system, where the corals experienced the greatest magnitude and duration of unusual warmth. These conditions were so extreme that even remote and well-protected reefs experienced bleaching events and coral deaths. However, for less extreme disturbances, of magnitudes more in line with natural variability, the reduction of additional human-made stresses in marine protected areas (MPAs) can make marine ecosystems more resilient to warming. Certainly over long timescales, the reef system was remarkably resilient to the massive changes in sea level and ocean environment associated with the growth and decay of ice sheets over the past 30,000 years, as Webster and colleagues report in this issue.

The ability of ecosystems to adapt to change weakens as the range of stressors increase. Modern marine ecosystems are facing not only sea-level rise and warming, but also the effects of human activities ranging from overfishing to dredging to enhanced runoff of sediments and nutrients. Designating ocean regions as MPAs can help to reduce at least some of these additional factors. The establishment of such areas has been increasing rapidly in response to losses in marine biodiversity. However, although all MPAs limit human activities and resource extraction in some manner, the degree of limitation and the level of enforcement vary. Areas with strict and enforced prohibitions on fishing show clear gains in total fish biomass and the size and diversity of fish $^{2}$; increases in biomass and diversity also extend to plant and invertebrate communities ${ }^{3}$.

There is evidence that thriving ecosystems within MPAs are more resilient in the face of environmental disturbance. Prior to 2016, areas of the Great Barrier Reef that were in protected regions were more stable and quicker to recover from bleaching events, episodes of coral disease, or storms than surrounding sites ${ }^{4}$. Certainly on longer timescales, prior to significant human influence, the Great Barrier Reef
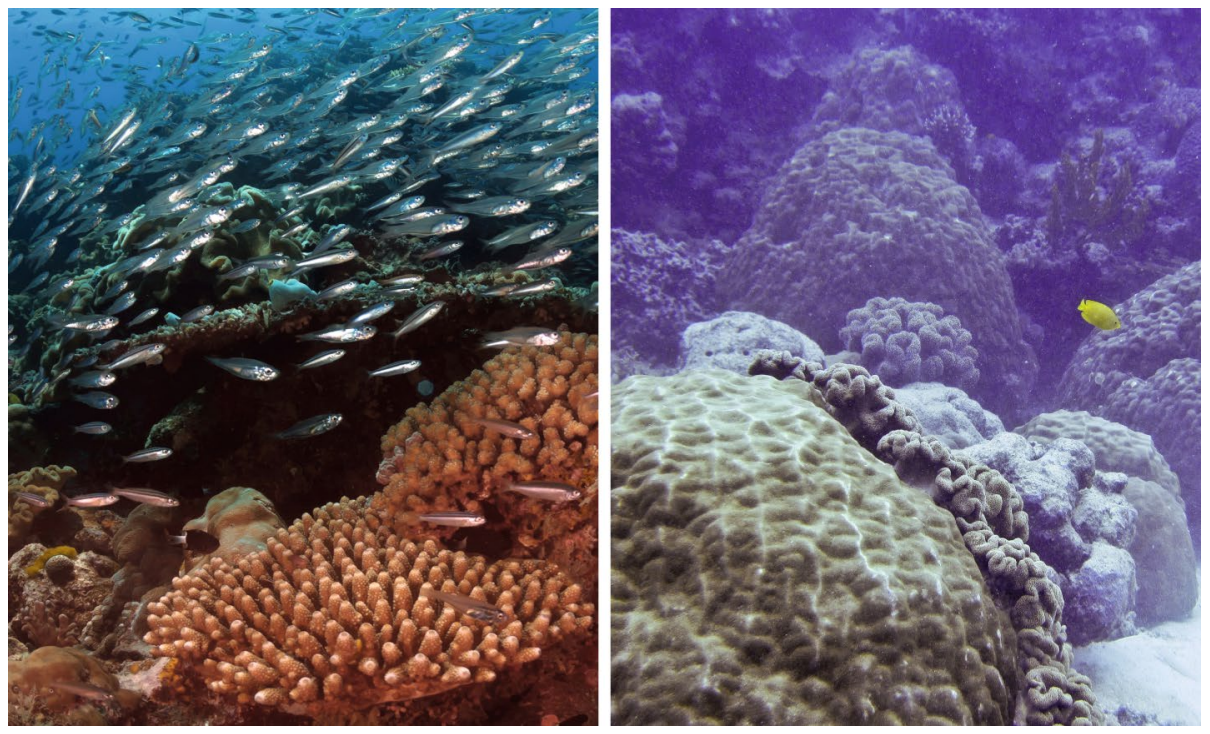

Credit: Left, Steffen Binke / Alamy Stock Photo. Right, Da Premium / Alamy Stock Photo

has proven adaptable to change. As sea level rose and fell by about 120 metres, the reef system migrated across the shelf to a more suitable depth, for the most part resuming coral growth and accretion within hundreds of years.

Of course, the environmental changes of the last glacial cycle provide little in the way of analogues to modern climate change. Rates of sea-level rise were lower, and ocean temperatures may never have risen to the levels experienced by today's corals. Nevertheless, there may be some lessons to help ensure the survival of the Great Barrier Reef and other similar ecosystems. The relict reef tracks span a transect that extends over a kilometre from the site of the modern reef. And the corals that settled on the incipient reefs were transported as larvae from nearby sites, which allowed rapid colonization. Adequate space for migration to more favourable conditions and connections that allowed an exchange of biomass with other, similar ecosystems seem to be key factors that supported the past resilience of the Great Barrier Reef.

In the modern ocean, the size of a MPA affects its effectiveness, with larger areas showing greater gains. The presence of a continuous habitat that allows the movement of fish across the boundaries of different MPAs also increases fish biomass ${ }^{2}$. Larval connectivity should also be included in any plans for MPAs, especially as larval duration may decrease in warmer ocean waters.

But as the coral bleaching and death events in 2016 and 2017 have shown, even strong protection from human activities cannot protect ecosystems when their thermal limits are surpassed. Under business-as-usual emissions, the community thermal-safety margin may be passed by 2050 in tropical ecosystems ${ }^{6}$. This will only be exacerbated by concomitant ocean deoxygenation and acidification.

Efforts to establish and strengthen MPAs can increase ecosystem resilience. But ocean warming and acidification must be curbed as well to ensure ocean health.

Published online: 31 May 2018

https://doi.org/10.1038/s41561-018-0158-9

References

1. Hughes, T. P. et al. Nature 556, 492-496 (2018).

2. Edgar, G. J. et al. Nature 506, 216-220 (2014).

3. Lester, S. E. et al. Mar. Ecol. Prog. Ser. 384, 33-36 (2009).

4. Mellin, C. et al. Ecol. Lett. 19, 629-637 (2016).

5. Álvarez-Romero, G. et al. Global Change Biol. 24, 671-691 (2018)

6. Bruno, J. F. et al. Nat. Clim. Change https://doi.org/10.1038/ s41558-018-0149-2 (2018). 